\title{
THE ROLE OF TRAINING IN PROVIDING OPPORTUNITIES FOR ENVIRONMENTAL AND NATURAL RESOURCE DISPUTE RESOLUTION
}

\section{JULIA WONDOLLECK}

During the past 10 to 15 years, considerable attention has been devoted to the potential, as well as appropriateness, of collaboration and negotiation in resolving environmental and natural resource disputes (Amy 1987; Bacow and Wheeler 1984; Bingham 1986; Carpenter and Kennedy 1988; Cormick 1980; Susskind and Weinstein 1981). Alternative dispute resolution processes seem to make sense both conceptually and empirically as illustrated by their actual application to environmental and natural resource disputes.

The management and allocation of common resources are inherently political undertakings, tasks often ill-suited to rational administrative decision-making processes. They are judgmental in nature, involving trade-offs between different groups in our society and between different resource uses. Moreover, these decisions are clouded by risk and uncertainty and frequently contain ethical or moral concerns about our responsibilities to future generations and to nonhuman species. Even at a theoretical level, decisions of such complexity and inherent controversy seem certain to fail if rational, scientifically based decision making alone is applied to them.

The idea that some environmental and natural resource disputes are amenable to resolution has proven itself (Bingham 1986). Disputes along the entire spectrum from wilderness or endangered species preservation, to industrial facility construction and operation, to local community housing or commercial developments, have been successfully resolved when the parties were encouraged to put down their weapons, set aside their positions, and collaborate in an effort

Julia Wondolleck is Adjunct Assistant Professor in the School of Natural Resources of the University of Michigan, Ann Arbor. 
to build solutions that would accommodate all the key interests and concerns of affected groups.

With all the attention, research, and seeming validity of the concept, it is not clear that the actual application of dispute resolution processes-whether successful or not-matches the enthusiasm of its advocates. There are many disputes today that, given our understanding (both theoretical and applied) of dispute resolution processes, should be amenable to resolution. Yet they continue to bog down administrative appeals and review processes, clog the courts, and eat away at the limited resources of the disputing parties.

Gerald Cormick (1980) suggested that four key factors need to be satisfied before effective negotiations could occur.

1. The recognition by all parties of the necessity of other parties participating in the decision-making process as co-equals. Fundamental differences that might preclude any party from acknowledging the legitimacy of another party must not be present.

2. Each of the parties must have sufficient power or influence to exercise some sanction over the ability of other parties to take unilateral action.

3. The parties must be able to commit themselves and their constituents to the implementation and support of any agreement reached.

4. There must be some sense of urgency on the part of all parties to end the dispute.

In other words, all parties must have the incentive to work together to try to settle their differences. The alternatives of protracted litigation, administrative or judicial decisions that bear little resemblance to the real concerns of affected parties, and resource expenditures in an adversarial arena that does not promise satisfactory outcomes, all provide incentives for disputing parties to settle their differences collaboratively rather than leaving the outcome to others. If the above four criteria are indeed being satisfied in many disputes, making them amenable to potential collaboration rather than adversarial resolution, why are many potentially resolvable disputes not being resolved?

\section{Providing Opportunities for Dispute Resolution}

Merely being "amenable" to resolution via an alternative process based on collaboration and negotiation does not then translate to this collaboration and negotiation actually occurring. If a dispute is amenable to resolution-if the affected parties have the incentive to negotiate-then one other factor must be present in order for an attempt to be made to actually resolve it: the opportunity must exist for this collaboration and negotiation to occur.

Providing adequate and appropriate opportunities seems to be the greatest stumbling block to resolving those environmental and natural resource disputes 
that are amenable to resolution. Although we have certainly made great strides in a relatively short period of time to broaden the opportunities available, these efforts still leave a large segment of disputes unaddressed. There are now statelevel dispute resolution offices in Hawaii, Massachusetts, Minnesota, New Jersey, and Wisconsin (Meeks 1985). The US Environmental Protection Agency, among other federal agencies, has experimented with formal regulatory negotiation processes which, if formally adopted, would institutionalize negotiation in the agency's administrative rulemaking procedures (Fiorino and Kirtz 1985; Harter 1984; Susskind and McMahon 1985). Similarly, some states have passed legislation governing the siting of hazardous waste treatment and disposal facilities that mandates negotiation between potential host communities and facility developers (Bingham and Miller 1984). Additionally, at a nongovernmental level, organizations such as ACCORD Associates, The Conservation Foundation, The Mediation Institute, the New England Environmental Mediation Center, and the University of Virginia's Center for Environmental Negotiation, provide viable forums when their expertise and facilitation are requested. In so doing, these professional facilitators and mediators provide opportunities where the parties were unable to do so on their own.

Theoretically, four conditions must be satisfied before we will begin seeing more alternative dispute resolution processes applied in the environmental and natural resources arena. First, government decision makers and their constituencies must have knowledge and an understanding of these processes. Second, these parties must all have the capability and skills to participate in a dispute resolution process effectively. Third, there must be institutional support within an agency or organization for pursuing such processes. Fourth and finally, the institutional structure, or process, must exist to accommodate it.

It seems unlikely that formal institutional systems will be (or should be) put in place before the merits of dispute resolution processes regarding particular issues have been illustrated or "proven" to a specific agency. Once agency officials observe the functioning of alternative processes on issues and in circumstances relevant to their situation, and understand its premise, then the potential for more formal application of dispute resolution techniques can be explored. This seems, however, to be a chicken and egg type of problem. Before institutional systems are in place any application is, by definition, ad hoc and must work against the procedural disincentives and skepticism that seem to impede effective dispute resolution to begin with.

How might the institutional understanding and capability be developed such that institutional support and structures will follow? One way in which to begin doing so is to train agency decision makers in dispute resolution concepts and negotiation skills and then to illustrate the application of these concepts and skills to their management and issue situations. A number of federal agencies have been doing just that for several years now including, in the natural resources area, the US Forest Service, National Park Service, US Army Corps of Engineers, 
Bureau of Land Management, US Geological Survey and Soil Conservation Service.

What has the consequence been? How useful can training be in fostering the resolution of disputes, in providing the opportunities that now seem to be lacking? The remainder of this article addresses these questions in the context of an evaluation of the US Forest Service's Natural Resource Conflict Management Training Program.

\section{The US Forest Service's Conflict Management Training Program}

When the late Senator Hubert H. Humphrey introduced legislation in 1976 mandating comprehensive national forest planning, he remarked that its purpose was "to get the practice of forestry out of the courts and back to the forests." Yet, in the US Forest Service's current national forest planning process, the agency has received over 600 administrative appeals on the first 72 plans completed as of April 1987. Moreover, these plans, according to agency officials, were "the easy ones." Agency officials estimate that they will receive 1,000 more appeals before this first round of 10-year planning is completed.

Conflict pervades the management of our national forests (Wondolleck 1988). There are timber sale proposals that have been caught for almost a decade in a cycle of administrative review, decision, appeal, litigation, and administrative review again. There are more than 1,000 oil and gas lease applications that are caught in this same cycle. Wilderness designation decisions that were expected to take 10 years have now been in controversy for over 20 years, with the end still not in sight. The comprehensive forest planning process that was intended to resolve many of these disputes is now itself being confronted by appeals and lawsuits.

This impasse in Forest Service decision making is rooted in the agency's many competing objectives, ranging from timber and fuels management and production, to wilderness preservation and recreation provision. This wide range of legislatively legitimized objectives has given both commercial and noncommercial national forest users the ability to contest successfully decisions running counter to their interests. Hence, when disputes arise between different groups about the appropriate management of a particular area, these disputes frequently impede professional forest managers from determining what their management responsibilities actually are, let alone fulfilling these responsibilities.

In 1982, the US Forest Service began contracting with ACCORD Associates of Boulder, Colorado-an organization specializing in environmental and natural resource dispute resolution-to conduct a conflict management training program for national forest land managers. The resulting training workshops have been designed to help land managers develop an understanding of the causes of conflict and build skills in negotiation, mediation, facilitation, and conflict assessment. 
The program involves an average of three training workshops per year. These workshops are approximately 4 days long and contain presentations on:

- Conflict Assessment: understanding why a particular conflict arises, what the underlying issues and stakes are, and what type of conflict manageinent strategy might most appropriately be applied to it;

- Negotiation: when negotiation might be appropriate to forest management disputes and what are the key aspects of the negotiation process;

- Facilitation: discussed as a consensus decision-making process involving specific techniques for successfully working with groups and individuals to address a particular issue;

- Mediation: what disputes might be amenable to more formal mediation and what the roles of third party mediators might be;

- Conflict Management Planning: what specific steps might be followed in implementing a conflict management strategy in a specific situation; and

- Communication Skills: how to understand the different concerns being raised, the specific issues underlying these concerns, and how to in turn effectively communicate with disputing individuals and groups.

The workshops are attended by individuals at all levels of the agency. District Rangers and Forest Supervisors (the key decision makers at the national forest level) are well-represented in the list of participants, which comprises a wide range of line and staff professionals at the forest, region, and Washington office levels.

The agency's objectives for these workshops are to prepare participants to be able to:

1. develop strategies to anticipate and resolve actual conflict situations, as applied to natural resource issues,

2. perform conflict assessment that can be shared by the parties to a dispute,

3. determine the circumstances under which the approaches of mediation, negotiation, cooperative problem solving, or meeting facilitation are appropriate,

4. determine the need for a neutral third-party mediator or meeting facilitator to help resolve a dispute,

5. have a basic understanding of negotiation, cooperative problem solving, and meeting facilitation skills through actual "hands-on" experience,

6. possess basic skills in negotiation and particularly facilitation techniques,

7. assess their individual competence in each of the approaches and identify skills which need improvement, and

8. identify how these approaches can be used in actual natural resource conflicts within their own jurisdictions (ACCORD Associates 1983).

The consequences of this program to actual resolution of forest management 
disputes were evaluated using a survey method supplemented with selected personal interviews and brief case analyses. A survey probing how agency participants have been able to apply the skills and concepts covered in the workshops and what obstacles, if any, they have encountered trying to implement these ideas was distributed to all 214 Forest Service participants in these workshops during the three years 1982, 1983, and 1984. Seventy-two percent of the participants responded. Several case vignettes were also developed, following indepth phone interviews with selected participants. These brief case histories present and analyze both the successful and unsuccessful application of dispute resolution processes to a range of different national forest disputes and management situations.

\section{Consequences of the US Forest Service Training Program}

What can training accomplish? What can we learn generally from the US Forest Service experience about the ability of this one strategy to provide opportunities for dispute resolution? Four areas of evaluation of the US Forest Service program are:

1. the perceived relevance of dispute resolution skills and concepts to participants' official tasks,

2. differences in how training program participants now handle conflict situations as opposed to how they would have dealt with the same situations before having attended the training workshop,

3. what obstacles participants have encountered in trying to implement these dispute resolution concepts, and

4. the specific situations in which the skills and concepts covered in the training program have been applied by participants.

\section{Relevance to Participants' Tasks}

Participants see great relevance between course concepts and techniques and their forest management responsibilities. It is certainly instructive that 90 percent of the respondents recommend the training program to others in the agency while only 8 percent do not. While not entirely different from what they feel they have always done on the job, participants do believe the program has allowed them to understand and manage conflicts better. The program provided participants with new insights into the scope and potential of their management tasks as well as helped them to improve upon methods and strategies that, they believe, have historically been a part of national forest management.

Participants were asked for their perceptions of how applicable conflict management techniques might be to some of the more divisive disputes that they encounter in managing the national forests, disputes that now escalate into appeals 
and litigation. Overall, two thirds of the survey respondents agreed that resolving these disputes is possible while 25 percent disagreed, indicating that most believe that these disputes are not an inevitable and unavoidable part of forest management but that they can be managed and resolved if given the chance.

Participants have been able to apply the skills and concepts acquired during the training workshops to a broad range of different situations and tasks. More than half of the respondents found the skills quite to extremely useful in making recommendations to other US Forest Service staff about how to proceed in a specific situation, in interacting with different national forest user groups, in conveying information to different individuals or groups, and in internal US Forest Service personnel or administrative affairs. About one third of the participants have found the skills and concepts useful in obtaining information from different individuals or groups, involving various groups in reviewing site-specific proposals, when developing guidelines or procedures for implementing Forest Service programs or policies, and in structuring and running public meetings.

Participants overwhelmingly believe that relying on a third party to help facilitate discussions between different groups involved in a dispute, including Forest Service officials, is justified at times; only 4 percent felt that doing so was not an appropriate thing to do. Sixty-two percent of the training program participants indicated that they either have previously used a third party, whether a professional mediator or a trusted agency official at arm's length from the dispute, or that they do believe they will encounter situations in which doing so might be justified. The survey data seem to suggest further that participants do view themselves, at least in part, as parties to particular disputes, not necessarily as objective intermediaries trying to find a middle ground between other disputing groups.

\section{Consequences for How Conflict Situations Are Handled}

Attending the training program has made a difference in how participants approach a conflict situation. Most training program participants have realized specific differences in how they handle conflict situations, who and how different groups are involved in the decision-making process relevant to a particular conflict, how the problems to be addressed in decision making are defined, and how and what data are collected in decision making. Additionally, the time spent, cost involved, and outcome of decision making now differ.

Two thirds of the respondents feel that who they involve in analysis or decision making as well as how these groups or individuals are involved is now noticeably different than before the training. Similarly, 66 percent indicated that the options and range of alternatives considered in decision making are now at least somewhat different. Furthermore, 74 percent believe that how a specific problem to be addressed is defined before and during decision making is now different. 
Participants discussed several other significant changes in their management efforts as a result of attending the training program. They feel that they now:

1. are better prepared for agency decision-making processes (they do more upfront analysis and planning, are more confident and disciplined in decision making, and the process itself runs smoother),

2. have a better appreciation of and openness to the different interests at stake, thereby making them more objective, listening more to what others have to say, and aware of several viable alternatives where they used to see only one, and

3. see more options in decision making.

For example, one Washington office participant commented that "I've learned to be more analytical. I examine conflicts for the real reasons for the disputes and for the areas of commonality. Previously, I was more resigned to conflict and disagreement as SOP." Similarly, a District Ranger commented that "I try to more systematically look for the people who are going to be affected by decisions in advance and solicit their involvement." Another responded that he is now "more sensitive to the thoughts and needs of others. I look more at both sides of an issue and I expect a positive outcome."

These changes may have benefits extending beyond the life of the specific disputes to which they were applied. To a large extent, disputes escalate and adversarial behavior is promoted when parties do not trust one another. In the environmental and natural resources arena it is this lack of trust that is at the heart of many disputes. Hence, if participants in conflict management training programs revise their procedure such that they listen more, involve people in different ways, are aware of their own biases and are open to broader sets of alternatives, then it is entirely possible that they are taking the necessary steps that will help rebuild trust and, in so doing, minimize the disputes that eventually do occur.

Responses to questions about how data are collected and what data are collected during decision making were fairly evenly matched with about half of the participants believing that these are both now different, 18 percent indicating that they are notably different. Responses to the question about how the amount of time consumed in decision making may differ were fairly evenly divided between a belief either that less time is consumed ( 31 percent), that more time is consumed ( 26 percent), or that there has in fact been no perceptible change ( 30 percent). There was more variation in beliefs about how the costs involved in decision making may now differ than was the case for time involved. Overall, 28 percent indicated that less cost is involved, 20 percent that more cost is involved, and 38 percent that there has been no change in this area.

Participants were also asked how the eventual outcome of decision making might now differ as a result of using conflict management concepts. While some participants ( 31 percent) felt that the eventual outcome of decision making differs 
little, if at all, from what would likely occur should they not employ conflict management strategies, 39 percent felt that there is at least somewhat of a difference, with 19 percent indicating that the outcome is quite a bit different as a result of these alternative processes. It is interesting to note that, of all the findings discussed in this training program evaluation (Wondolleck 1986), one of the few items the US Forest Service Chief chose to highlight in his Friday Newsletter (May 15, 1987) was this latter point about the outcome of decision making differing only marginally from using such a process. Apparently his office feels that agency officials will be more apt to employ conflict management strategies in their decision making if they feel that it will not significantly change how, in fact, on-the-ground management of the national forests proceeds.

\section{Obstacles to Implementing Conflict Management Concepts}

In general, most participants reported few barriers to using conflict management processes. The survey results indicated that:

1. most agency participants do not feel that existing procedures and guidelines unduly constrain their application of conflict management concepts,

2. with some exception, there is support from other agency personnel for trying conflict management procedures when appropriate,

3. financial constraints do not often enter into the picture when considering or employing conflict management processes, and

4. the skills transferred in the training program are relevant to most Forest Service positions held by program participants.

While most participants do not feel unduly constrained in their application of conflict management processes, 30 percent of their colleagues disagree and, moreover, do so vehemently. In their responses, these participants expressed strong feelings about a lack of support within the agency for conflict management processes. These agency limits included individuals not understanding, and hence not supporting, the ideas, that they are defensive of current standard operating procedures, that leadership for change in this direction is lacking, or that the needed assistance in following through with a conflict management strategy simply does not exist. For example, one individual commented that "the real problem is not the usefulness of the ideas and material, but rather the (a) willingness of the polarized interests (eg, USFS, the administration, the environmentalists, and the timber industry) to even want to approach the idea of compromise, consensus, win/win to avoid conflict, and (b) the inability to influence top managers to seek peace with old enemies." Another concurred: "The agency is not responsive to conflict resolution. Many of their postures generate rather than reduce it. Governmental management in my unit is so hidebound I see little opportunity for successful conflict management until drastic changes are made in the organization." One participant felt that the obstacles he has encountered 
were due to a "lack of understanding of what conflict management is all about on the part of Forest Service management. I've never had any problems with the public or peers; it's the line authorities who resist. They feel that they are giving up their decisionmaking authority." This sentiment was echoed by another participant who wrote: "What one does run into sometimes are old school Forest Service types to whom these ideas are brand new and represent a change or a threat." Some participants expressed concern as well about their ability to follow through with a conflict management process, or more general time and logistical constraints that at times impede their use of these processes. This one third of the participants that have encountered obstacles to implementing conflict management concepts also represents those who spent considerable time on their survey responses, providing much more detailed information about their experiences than did the other respondents.

Twenty-eight percent of the participants indicated that they had tried unsuccessfully to apply conflict management skills to their jobs; all but two individuals provided a reason why they thought they had been unsuccessful. Most of the explanations fell equally into one of two general categories.

1. One or more of the disputing parties had not participated in good faith.

2. They had encountered difficulties posed by the agency itself or the individual official running the process, resulting from either a lack of commitment to the process, inadequate preparation for the process, or a need for additional training and skills.

Training program participants were asked to evaluate the degree to which they need additional training in conflict management. Their responses fell into two different categories.

1. A need was perceived for additional specific skills, whether they be "people" skills (ie, how to interact with different groups or individuals under varying situations) or "process" skills (ie, how to structure and run various conflict managing processes).

2. There was needed an understanding of how to transfer the skills already acquired in the training program to "real world" situations. This response encompassed both the expected difficulties in converting theory to practice and, perhaps more passionately, how to convince those colleagues and superiors who did not attend the training program of the benefits of alternative processes in some situations.

The fact that some participants desire additional training is not surprising. There are obvious limits to how much can be covered in a 4-day session, regardless of how comprehensive it might be. Furthermore, now that the participants are back on-the-job they have a better understanding of exactly where and how the conflict management concepts might be applied. Hence, further training now would have more meaning; participants know what they need and where they would apply it. 


\section{Specific Case Applications of Conflict Management Concepts}

Much of the survey results discussed above probed participants' perceptions of the usefulness and consequences of the training program. Understanding these perceptions is one step towards assessing the program's effectiveness. An additional step in discovering how and where course learnings were translated to change on-the-job is probing case examples of how and when participants have used their new skills in specific situations.

Program participants were asked to describe one or two representative situations in which they had applied these skills and concepts covered in the training workshop. Half of the respondents answered this question by providing at least one case example. The case examples fell into ten broad categories:

1. conflict management processes involving the Forest Service and a single national forest user group,

2. processes involving the Forest Service and more than one user group (multiparty disputes),

3. an agency official serving as a third party facilitating a dialogue between other disputing groups,

4. a Forest Service official using conflict management concepts in giving support or making recommendations for specific actions by superiors, peers, or subordinates,

5. communicating with different groups and running informational meetings,

6. setting internal agency strategy or policy on a specific issue or problem,

7. building consensus in the National Forest Management Act forest planning process,

8. resolving disputes that have reached the appeals stage,

9. in intraagency administrative affairs, particularly communicating with other colleagues in interdisciplinary team settings, and

10. in personal affairs.

Participants' responses to this question illustrate that they have been able to creatively adapt program learnings to different Forest Service roles and tasks. The level of detail provided and the nature of the application or conflict management process used varied considerably among the responses. However, each represents a different type of situation in which the skills and concepts have proven useful.

\section{The Role of Training in Providing Opportunities for Dispute Resolution}

If the training program used by the US Forest Service is representative of those employed by other agencies, then it appears that training can be quite useful in providing broader opportunities for dispute resolution. It provides these opportunities by changing agency officials' understanding of the conflict situations 
that they encounter, by altering how officials interact with their constituent groups, how and what data they apply to decision making, and what alternatives they consider. Each of these things critically changes the dynamic that is established between the agency and interested groups and individuals. They foster trust rather than distrust, build understanding rather than misunderstanding, and, open forums for the creative development and joint assessment of alternatives, alternatives' that might more directly and fully accommodate the interests of a range of different groups. Furthermore, once this relationship and dynamic is set in place it builds upon itself, providing longer lasting benefits to future interactions involving the agency and those groups and individuals with a stake in its management decisions.

Analysis of both successful and unsuccessful attempts to resolve natural resource disputes indicates that, in some situations, perhaps the most valuable impact an agency official can have is not in determining what decision or outcome is finally achieved but often in how those decisions are made: who is involved, how issues are framed and their consideration bounded, what information is brought to bear, how alternatives are developed and then analyzed and evaluated, how trade-offs are made, and how implementation and monitoring then occurs (Wondolleck 1985). In these cases it is not just substantive data that are needed to direct decision making but, in addition, the procedural concern about how decisions are then formulated given these data and the role of affected groups and individuals in making the judgmental assessments that are a part of the final decision (Bacow 1980). Those decision makers who understand how to structure and facilitate such processes are those who are now successfully providing the necessary opportunities for the collaboration and negotiation that eventually lead to disputes being resolved.

Training appears very useful in changing the tone and direction of existing processes and of encouraging experimentation and creativity within the bounds of established administrative procedures. It is interesting to note that most participants did not view the notion of conflict management as differing that much from what they felt their role has always been. Rather, the training seems to have simply given them a new lens through which to understand what is going on in a conflict situation and hence what they might best do to manage it. Through training, agency decision makers build an understanding of how important is the process they use in their evaluation and decision making to effective conflict management and dispute resolution.

The survey research results described above clearly illustrate the usefulness and potential of training. At the same time, however, the findings illustrate the very real and very formidable obstacles that many agency officials confront when trying to apply dispute resolution concepts to their management tasks. In order to overcome the obstacles posed institutionally by a seeming skepticism of and bias against alternative dispute resolution, observation of and experience with these processes is necessary. The only way this observation and experience will 
be brought about is by the dissemination of information about those cases where disputes are effectively resolved, cases published in professional journals or magazines, presented through the news media or described in reports by thirdparty intervenors to the agencies or organizations involved in a dispute resolution process. Experience can also be provided by having key policymakers closely or directly involved in a dispute resolution process. This latter approach is not as easily accomplished as the former, however.

Training will increasingly play an important role in surmounting institutional obstacles to alternative dispute resolution by helping to provide the opportunities during which observation and experience can occur. The benefits of training are derived at two levels. First, training builds understanding of and ability in dispute resolution among those directly participating in the training. Hence, it encourages dispute resolution efforts by these participants and provides the occasion for others in an agency or organization to observe and, at times, experience the effort. Second, and perhaps seldom realized, in so doing training provides institutional experiences and opportunities for observation in a fairly benign and nonthreatening way. It provides an opportunity for the organization to experiment with the idea without formally committing itself to it through institutional changes that might adopt conflict management concepts and techniques within existing administrative processes. Organizations are more apt to consider and employ noncommittal training efforts whereas they may give little serious consideration to more formal administrative changes, regardless of how temporary or experimental they are intended to be. In building this record of experience and observation it provides an opportunity for the organization to judge for itself the appropriateness of dispute resolution to its management tasks and how to foster it as desired and appropriate. In fact, this outcome is precisely what we are now seeing to some extent in the US Forest Service. The US Forest Service Chief's comments in the May 15, 1987 Friday Newsletter, draw selected lessons from this training evaluation in hopes of encouraging the more widespread application of dispute resolution efforts in the agency, particularly in the current national forest planning process.

One hypothesis at the outset of this research was that training would likely be delivering only marginal change; that if no institutional context existed within which to apply the lessons of training, that the training's usefulness would be minimal. The research results indicate, however, that training provides an important medium through which institutional learning can occur and institutional changes might be brought about. Change does not come about overnight in other arenas and we should not expect it to happen with alternative dispute resolution processes either. Furthermore, it is not clear that we should necessarily want it to. Before major change is instituted we should experiment with it, observe its functioning and its impact and evaluate its appropriateness for specific situations. This gives agency officials and interest group leaders the opportunity to see how it might work for them and to pursue it as desired. 
What would be much worse would be a rush to employ alternative dispute resolution processes without this understanding and in inappropriate situations, potentially only reinforcing existing skepticism and bias against the idea that some natural resource or environmental disputes might indeed be resolvable if only given the chance. By training agency officials in conflict management skills and concepts, a more informed, albeit cautious, avenue for change is provided.

\section{Recommendations for Maximizing the Benefits of Training}

The training program described and evaluated in this article could easily be left intact, with no changes in content or structure, and the benefits and outcomes discussed here would most likely continue to be realized. The course is highly regarded and overwhelmingly recommended by past participants to others in its current form. It does appear possible, however, to further capitalize on the foundation already laid by this program and, in so doing, to potentially provide additional opportunities for dispute resolution in the future.

For the most part, participants valued both the workshop content and its structure. The mix of conceptual ideas and hands-on skills seemed to satisfy participants' needs. While some individual preferences obviously differed (eg, some wanting more on mediation and others wanting less), as an introductory session the workshops seemed appropriately structured to address, in some depth, the varied needs of most participants. The survey analysis seems to suggest that any major content change would only serve one group at the expense of another.

However, the one quite consistent issue raised during this evaluation is that many participants have encountered difficulties in trying to convert what they perceive to be very valuable learnings from the course to practice on their jobs. It is always difficult to convert the content of an intense 4-day session to practice, to transform learnings that in the classroom made sense but that once back onthe-job are perhaps not as easily implemented. Hence, one critical step towards expanding the benefits of any training effort is to directly address this difficulty. There are five key ways in which to begin doing so.

First, include a section within the training workshop that specifically addresses implementation issues. During this section the participants and trainers could join in discussing:

- what the costs and benefits of conflict management might be to several agency or organization specific disputes,

- how to go about educating colleagues and superiors whose assistance is needed in implementing a conflict management process,

- how to obtain the support of others who did not attend the training and/or who might be skeptical of conflict management concepts, 
- what might be "negotiable" in different management or administrative situations, again specific to the agency or organization attending the training,

- how to build trust on the part of the public (addressing the concern that some disputes are a result of past actions and continuing public mistrust of the agency or organization),

- what specific disputes currently being confronted by the agency or organization might be amenable to conflict management processes, and

- ways in which participants might continue building skills once back-on-thejob (addressing the concern that participants will "need more training" before they will feel comfortable applying the ideas and skills acquired at the training session).

Second, keep the training as agency or organization specific as possible. Use exercises and examples that are tied to issues and situations relevant and current to those in attendance. Additionally, have the exercises and examples reflect the range of different types of applications of conflict management skills by past participants.

Third, one way to encourage participants to creatively apply conflict management approaches as appropriate and to feel more confident about the skills they acquired through the training is to establish an ongoing network between those in the agency interested and skilled in conflict management. This network could be as formal as a periodic newsletter that keeps individuals informed of what their colleagues in other offices, divisions, or regions have been doing, including new ideas or suggestions from the conflict management profession, or it could be more informal, perhaps a mailing of inserts for the training handbook, if one is used, or write-ups of both successful or unsuccessful cases using conflict management in various management or administration situations. The data suggest that there is dispute resolution activity occurring that is going unnoticed. These experiences could provide instructive examples to others in an agency or organization, both in making informed decisions about formal support for the application of dispute resolution concepts as well as at the participant level in employing the skills they have already acquired.

Fourth, when possible send whole management teams, particularly in high conflict areas, to the training so that a mini-network within an agency division, department, or region can automatically be established. In so doing, a broad understanding and support base will be formed to implement more effectively conflict management processes as appropriate.

Fifth, institute an in-house capability for dispute resolution. A 4-day training program is certainly not going to give participants all the skills necessary to follow through with a complex dispute resolution effort. Additional support either from within the agency or from professionals skilled in mediation, facilitation, and dispute resolution should be accessible as well to maximize the usefulness of the training. An in-house conflict management advisor or facilitator could 
provide assistance, suggestions, and support for the application of conflict management processes in different situations. This source of assistance might also diminish the feelings on the part of some training program participants that additional training is needed before they will have sufficient confidence to follow through with a dispute resolution process. Additionally, this in-house capability provides a nonthreatening way for an organization or agency to experiment with conflict management concepts and processes without more formally supporting or adopting them.

\section{References}

ACCORD Associates. 1983. Natural Resource Conflict Management Workshops Contractor's Final Report. Boulder, CO: ACCORD Associates.

Amy, D. 1987. The Politics of Environmental Mediation. New York: Columbia University Press.

Bacow, L. S. 1980. The technical and judgmental dimensions of impact assessment. Environmental Impact Assessment Review 1(2):109-124.

Bacow, L. and Wheeler, M. 1984. Environmental Dispute Resolution. New York: Plenum Press.

Bingham, G. 1986. Resolving Environmental Disputes: A Decade of Experience. Washington, DC: The Conservation Foundation.

Bingham, G. and Miller, D. S. 1984. Prospects for resolving hazardous waste siting disputes through negotiation. Natural Resources Lawyer 17(3):473-489.

Carpenter, S. L. and Kennedy, W. J. D. 1988. Managing Public Disputes: A Practical Guide to Handling Conflict and Reaching Agreement. San Francisco: Jossey-Bass.

Cormick, G. W. 1980. The "theory" and practice of environmental mediation. The Environmental Professional 2(1):24-33.

Fiorino, D. J. and Kirtz, C. 1985. Breaking down walls: Negotiated rulemaking at EPA. Temple Environmental Law and Technical Journal 4(1):29-40.

Harter, P. J. Winter 1984. Regulatory negotiation: The experience so far. Resolve $1: 3-7$.

Meeks, G. Jr. 1985. Managing Environmental and Public Policy Conflict: A Legislator's Guide. Denver: National Conference of State Legislatures.

Susskind, L. and McMahon, G. 1985. The theory and practice of negotiated rulemaking. Yale Journal of Regulation 3(1):133-165.

Susskind, L. and Weinstein, A. 1981. Towards a theory of environmental dispute resolution. Boston College Environmental Affairs Law Review 9(2):311-357.

Wondolleck, J. 1985. The importance of process in resolving environmental disputes. Environmental Impact Assessment Review 5(4):341-356.

Wondolleck, J. 1986. An Evaluation of the US Forest Service Natural Resource Conflict Management Training Program: Final Report. Ann Arbor: The University of Michigan School of Natural Resources, Environmental Conflict Project.

Wondolleck, J. 1988. Public Lands Conflict and Resolution: Managing National Forest Disputes. New York: Plenum Press. 